\title{
On the Perception of Linkages between Food Consumption and Health in Poland
}

\author{
Agnieszka Maj \\ Faculty of Social Sciences, Warsaw University of Life Sciences - SGGW, Poland
}

Copyright $\subseteq 2016$ by authors, all rights reserved. Authors agree that this article remains permanently open access under the terms of the Creative Commons Attribution License 4.0 International License

\begin{abstract}
This article endeavors to identify a number of widespread beliefs currently shared by Polish people in relation to food and health, and to present these viewpoints within the context of various lifestyle changes that have been taking place since the political and economic transition in Poland started. The research, based on a survey conducted on a group of selected participants from Poland, took place in July, 2015. It focused on the participants' attitudes and beliefs concerning the kinds of food they considered healthy or unhealthy, as well focusing on their perception of the linkages between healthy eating, and being able to maintain a level of physically self-satisfying appearance. To broaden the scope of analyzes, one of the most interesting findings of the study refers to the results of two other recent nationwide surveys: the survey of dieting and eating habits of the Polish, as conducted by the Public Opinion Research Center (CBOS), and the study of changing eating habits of the Polish people conducted by Domański et al. in 2013.
\end{abstract}

Keywords Poland, Eating Habits, Transition Process, Lifestyle, Food, Health

\section{Introduction}

Poland is a former communist-ruled country located in the heart of Central Europe, with a current population of almost 38,5 million people. Although the political transition into democracy, followed by implementation of a capitalist economic system, began over 26 years ago, we are still able to observe how the results of this transition process are influencing the everyday lifestyles of Polish people. One particular aspect of this has been the subsequent change in eating habits.

Thanks to the influence of the mass media, and coupled with the freedom to travel without the earlier restrictions imposed on them by the communist system, Polish people have discovered a great variety of culinary delights, which includes new types of food and news ways of preparing it. For instance, the mass media have been instrumental in popularizing food high in nutritional value, while on television cookery shows, they explain to their viewers that cooking and eating are socially meaningful activities, that they can be used in order to express one's originality or to help one accustom themselves with the latest culinary trends. As a result, we can observe a genuine flourishing of alternative ways of eating, and their accompanying dietary fashions.

As a sociologist, I am particularly interested in those changes in lifestyles as expressed in body maintenance practices $^{1}$. In this article, I would like to take a more detailed look at the recent changes and developments in the eating habits of the Polish. In particular, I have decided to focus on one explicit aspect of eating habits, namely, the perception of the relationship between food and health. I would like to slightly get away from the research perspective, which focuses on the socioeconomic aspects of the concept of lifestyle and interprets eating habits as an expression of 'taste,", although I am going to refer to this kind of research as well. My goal is rather to give some insight in the beliefs concerning linkages between the consumption of various kinds of food and the maintaining of one's health and the cultural understanding of what constitutes healthy eating.

As it has already been noticed by Giddens, with reference to the changing patterns of consumption of food, eating habits can be considered a part of lifestyle: "Everyone in modern societies is 'on a diet' since the advent of supermarket culture and global food production. That is to say, everyone has to decide what to eat in relation to how to be - how to live their lives" [1, p.137]. However, much as the free market can be seen as a liberating force, giving way to the proliferation of various styles of consumption, it can, on the other hand, also bring pathology, since "habits, once established, can turn into compulsions, and create a downward spiral which the individual finds it difficult or

\footnotetext{
1 I understand "body maintenance practices" as all kinds of practices, which are undertaken in order to shape our bodies according to our own desires as well as social expectations: the practices which are to improve the personal appearance, health and general well-being of our bodies.

2 This perspective is used for example by Warde, who notices: "Though partly an aspect of bodily reproduction, culinary practice is also associated with lifestyles and, one supposes, is the ultimate metaphorical source of the concept of taste" [7]. See also: $[6,8,9]$.
} 
impossible to control" [1, p. 137]. Giddens gives obesity as an example. I believe, that researching eating habits can help predict, what kinds of health problems are to be expected in the future, and how the already existing and widely held beliefs concerning relations between food and health can be used as a starting point in educating citizens. The first legislation acts promoting healthy diets, have only recently been introduced in Poland in September of 2015 ${ }^{3}$.

In order to best illustrate and identify the popular beliefs of Polish people in connection to the influence of food on health, I will use a sociological perspective. I will refer to the results of a research survey, which I conducted on a group of 65 research participants, all from Poland, in July, 2015. Furthermore, to broaden the scope of my analysis, and to present my findings in the larger context of the entire Polish population, I will refer, where applicable, to the results of two other recent surveys. First of them is the survey of dieting and eating habits of the Polish, as conducted by the Public Opinion Research Center (CBOS), an independent, publicly funded research centre in Poland, in July, $2014[3]^{4}$. The second, presents some recent changes in the eating habits of the Polish people within the context of chosen aspects of social stratification and it was conducted by Domański et al. in $2013[4]^{5}$.

\section{Materials and Methods}

The main purpose of the research was to explore and deepen the knowledge of the participants' perception of the relationship between food and health. The study was designed in order to learn more about the beliefs concerning linkages between the consumption of various kinds of food, the maintaining of one's health and preserving what was thought to be a healthy and 'better' appearance. It was important to learn about the participants' attitudes to the normative discourses that emphasize the importance of leading a healthy lifestyle, as well examining their knowledge of the rules of healthy eating. I was interested in both the expert, and the widely held apparent knowledge among Polish people, that referred to the sphere of what healthy eating constituted, and which was present in the beliefs of the research participants selected.

Five main areas of focus, derived from reading the topic literature, were distinguished:

1. The understanding of healthy eating

2. The characteristics that comprised a proper nutritional diet

3. The possible reasons of dieting and any developing interest in following new trends in dieting or dieting fashions

3 The above mentioned legislation act listed ingredients which should be avoided when preparing meals for children to be served in school cantines as well as it defined products which should not be sold in school shops because of containing unhealthy substances.

4 CBOS's research [3] was made on a representative, randomized sample of 943 adult Poles in July of 2014.

5 Domański et al. [4] conducted their study in 2013 with the use of CAPI method, on the representative, randomized sample of the Polish people over the age of 14 .
4. The sources of information concerning dieting used by the research participants

5. The kinds of food considered by them as healthy or unhealthy

The Internet is a commonly used source of information and reference concerning eating habits and dieting. Therefore, a self-administered online survey was used in order to reach people potentially interested in healthy eating. I was aware of the fact, that using online research tools raises concerns of authenticity of the obtained research material, but on the other hand, similar questions of authenticity may arise in "more traditional research and interaction environments" [see:5, p.456].

The research participants' interest information in healthy eating was the main criterion for eligibility in the study. The snowball sampling was used as a research method. At the initial stage of the research, four informants from various social backgrounds were chosen. They were asked to complete the questionnaire in order to test it for its appropriateness. Afterwards, each of them was asked to nominate three other research participants, who would meet the eligibility criteria of the study. The procedure of nominating new participants by the participants earlier included in the study was repeated. In total, the questionnaire was completed and returned by 65 research participants ${ }^{6}$.

The questionnaire contained multiple choice and open-ended questions. The multiple-choice questions were used only as filter questions, in order to determine the participants qualified to answer more detailed questions ${ }^{7}$. They were usually followed by open-ended questions. The participants' answers to open-ended questions were coded. The coding process was aimed at identifying common patterns and themes across all the answers. As G.W. Ryan and H. R. Bernard notice: "some short open-ended questions on surveys can be considered free lists, as can some responses generated from in-depth interviews and focus groups. Investigators interpret the frequency of mention and the order in which items are mentioned in the lists as indicators for items' salience. (...) The co-occurence of items across lists and the proximity with which items appear in lists may be used as measures of similarity among items" [6, p. 770]. The results presented below were arranged according to the most significant themes identified during the analysis of the gathered research material.

\section{Results}

\section{The Understanding of Healthy Eating}

For research purposes, an important information was if

6 The study did not encompass representatives of all socioeconomic statuses in the Polish population, but the references to the nutritional status of the whole Polish population will be provided in the "discussion" part of the article. The main sociological characteristics of the group of research participants were: higher education (all of them had college or higher education), gender (three fourths of them were women) and the place of residence (most of them were the inhabitants of big cities).

7 For example, to select participants who were on a diet and then ask them further questions concerning their dieting habits. 
participants led a healthy lifestyle. Three fourths of them declared that they were indeed trying to lead some kind of healthy form of daily routine. When describing what they understood as a healthy lifestyle, they placed healthy eating in first place.

They also associated leading a healthy lifestyle with physical exercise, taking care of one's health and living in a healthy environment, which also meant protecting the environment. Their definition of healthy eating illustrated that they were very conscious of the relationship between nutrition and health. For example, healthy eating was defined as: "The way of maintaining health, well-being and perhaps a chance for a long life" (R3) or "The way of supporting one's health" (R10). But it was also understood as a way of life: "It's the way of life. It changes your way of thinking and makes other people think you must be insane if you really want to eat all this healthy food instead of junk food. It's an individual choice. It's expensive" (R64).

When asked about the characteristics that comprised a proper nutritional diet, the participants most often cited a rational choice of food, which they understood to mean food that was healthy and eaten in moderation, thus following patterns of supposed healthy consumption, despite there being obvious temptations to eat food considered unhealthy. It was clear that the participants believed that it was unhealthy to eat just any kinds of food products they wished, and that without any concern about the influence of such food products on their health, was both irrational and irresponsible. Among the many other important characteristics of what they thought was a healthy diet, the participants indicated a well-balanced program of eating, one that should accordingly respond to the individual nutritional needs of one's body. Finally, the participants raised the issue of the quality of the food they consumed, identifying a healthy diet as one based on products of a good quality and high nutritional value. In general, they believed food products not produced through processed means, preserved more of their nutritional value. Consequently, they believed that eating such food improved one's health. For this reason, some of the participants preferred buying food from local producers rather than from supermarkets, and they usually spent time searching for "natural" products, or "products made in a natural way".

\section{Dieting}

Almost one third of the research participants admitted having been on a diet within the twelve months preceding the survey, and therefore showed considerable understanding and knowledge of the variety of diets that were available to them. They were also not only able to name the diets, such as the macrobiotic diet, the Copenhagen diet or 5 elements diet, but were also competent in describing the instructions and rules of the dieting processes. The most significant factor in eating healthily as chosen by the participants, involved eliminating certain kinds of food from their everyday diet, or a reduction in the intake of the kinds of food perceived as unhealthy, which they believed was tantamount to healthy eating. The kinds of products they chose to avoid consisted of various kinds of meat and products containing fat and salt.

Among the participants who had gone on a diet, the most popular motivations were the desire to lose weight, to look better, an improvement in their sense of well-being and an attempt to combat health problems. Only one participant admitted to having gone on a diet due to the fashion for dieting in their social environment. Those who admitted, that it was important for them to maintain a slim body admitted eliminating certain kinds of food products in order to reduce weight, many of which were mostly confectionaries.

Asked if they were following new trends in dieting, or if they had heard of any recent dietary innovations, almost half of the participants admitted they hadn't been following the latest nutritional dietary developments, while those who answered positively were able to list several. For example, some participants had heard that drinking barley extract (wheat extract was also mentioned), was believed to help people become slimmer. Another example was that the consumption of dark chocolate, though perceived as a sweet, was now judged to be healthy because it was not fattening.

Of those sources that proved most popular for information on dieting, were word-of-mouth (friends), and the Internet. Magazines and newspapers were also influential, as were various family members. Such answers highlighted that the participants obtained their information about dieting from the mass media and from people who occupied their immediate environment. It is also important to note that some participants sought professional advice, which they achieved though specialist books on the subject of dieting, or by visiting specialists such as doctors, dieticians or even Chinese medicinal advisers.

\section{The Common Beliefs Referring to the Kinds of Food Considered as Healthy or Unhealthy}

Having no assumptions of what food might be considered healthy or unhealthy, I asked the research participants to name five food products that they deemed healthy, and five that they thought of as unhealthy. It became instantly clear that their knowledge was very up-to-date, and that their eating choices followed with unerring precision rules and stipulations as laid down for a healthy eating lifestyle.

The participants then went onto to list what food products were essential in maintaining a healthy diet, including all fruit and vegetables, cereals such as whole grain bread, certain types of dairy products, and fish and meat. The participants also detailed products whose nutritious properties had been widely discussed throughout the mass media, with such examples as stevia or amaranth proving popular. The participants were also familiar with the fact that drinking lots of water helped in retaining one's health.

The unhealthiest food products that the participants listed were alcohol, confectionaries, crisps, fast food, sweet carbonated drinks and white bread. The participants also listed certain ingredients added to food during the process of 
mass production, especially saturated fats, preservatives, glucose-fructose syrup or mechanically separated meat. This indicated that they had a certain level of knowledge pertaining to the methods used during the mass production of food, and as to the drawbacks of what this entailed for the consumer. There was also a degree of uncertainty about types of meat like beef or poultry, the participants talking about how the breeding of these animals on big farms in kettles and being routinely treated with antibiotics, lowered the nutritious value of the meat, or in some cases, made the meat dangerous to eat. Among the other products the participants decided were of an ambiguous status were coffee, tea and chocolate. For some of the participants, it was obvious that these products had a positive effect on one's health, while for others their effect was rather negative. There were also some ambiguity concerning whether or not butter and milk had any detrimental influence on one's health, too.

What was of considerable interest was how the participant's perception of the linkages between food and health lay in the generality of food combination rules, such as which food or drink worked together or not. For example, participants claimed that a salad should exclude containing both cucumber and tomato, since this would reduce their nutritional consistency. The participants also believed they should only eat certain kinds of food at certain times of the day, such as not consuming fruit after three in the afternoon. Likewise, the last meal of the day should be at least an hour before going to sleep, and that no form of liquid should accompany the meal, and that one should drink at least thirty minutes after the meal.

\section{Discussion}

The existence of the aforementioned beliefs about the general rules for consuming food was further confirmed by the results of the research in regards to the dieting and eating habits of Polish people, conducted in the representative sample by the Public Opinion Research Center (CBOS) in July, 2014 [3]. According to the survey, among the most commonly shared beliefs referring to food, there was the belief that meat produced on large farms contained antibiotics. Among the other attitudes towards healthy eating shared throughout the Polish population, was that drinking a lot of water helped maintain health, or that eating a lot of fatty meat or products containing sugar, was bad for one's health.

The survey also confirmed that the most consistently popular diets among the participants were ones that eliminated food products that would ostensibly help to reduce body weight once removed. In most cases, the products most often eliminated or reduced were sweets, sugar or products containing fat. All these findings have also appeared in my research.

One of the findings of the nationwide CBOS poll seems particularly significant, as it may indicate changes that are taking place within the sphere of eating habits among the Polish nation right now. When asked about the similarity of their eating habits compared to those of their parents' generation, $40 \%$ of participants said their eating habits were appreciably different from those of their parents [3]. The representatives of this group were mostly well-educated people with high incomes, who occupy high social positions on the social ladder. This finding might somewhat indicate the intergenerational changes in lifestyles of these respondents, as reflected in their choice of alternative ways of eating.

The research concerning the ways in which lifestyles are expressed through practices of everyday life, especially eating practices have been undertaken in many European countries [for example: 8-9]. They have been recently initiated also in Poland by Domański et al. [4] $]^{8}$. The results of Domański's research confirm, that people occupying the highest positions on the social ladder, with higher education, to a greater extent that the representatives of other social strata, tend to choose the kinds of food which have positive effects on health [4, p. 204] and that they are more willing to avoid those, which are labelled by nutritionists as unhealthy (for example products containing fat or sugar) [4, p.94]. What is more, when comparing between men and women, these are women, who are more interested in eating healthily [4, p.85]. This finding seems to be similar to the findings of studies conducted in other European countries. For example, Warde $[9$, p. 84] points out, that there are three social characteristics of a respondent, who choses "healthy" food products: being a woman, living in the middle-class household and being highly educated ${ }^{9}$.

According to Domański et al., the globalization processes have not undermined the traditional ways of eating in Poland so far but this is going to change in the future, as the percentage of the representatives of the middle class, who are willing to adopt new eating habits is expanding [4, p. 230]. However, Domański et al. are cautious about the thesis, that the representatives of the middle class tend to treat the choice of food products as a way of expressing their social position. According to the scientists cited, the Polish people are rather reluctant to choose any 'exotic' kinds of food [4, p.230-231].

Joanna Cichecka, an author of an article concerning relations between diet and social capital [10], mentions two trends that refer to attitudes towards food observable in modern day Poland. The first of these is the general preference for organic food produced in an ecological way, which the Polish are currently popularizing across the nation. The second is the renaissance of regional cuisines [10, $\mathrm{p}$. 159]. This echoes the first of the mentioned trends conspicuous in the opinions of my research participants, who recognized that a diet based on natural, organic products was

8 This quantitative research was conducted in 2013, with the use of CAPI method, on the representative, nationwide, randomized sample of 2361 Polish people over the age of 14.

9 Also my research participants were mostly women with higher education. They perceived healthy eating as the most important characteristic of a healthy lifestyle and their choices of healthy and unhealthy products follow exactly the rules of healthy eating lifestyles. 
one of the very basic rules for eating healthily. They also expressed their uncertainty about the positive effects of eating meat, and were especially critical about the way in which the meat was produced. For some of them, the process of mass production of meat had a negative effect on its quality, which became a motivation to look for alternative forms of nutrition. This might be interpreted with reference to Ulrich Beck's notion of the 'risk society'. Among potential sources of risks in contemporary societies he mentioned the effects of chemicals on foodstuffs [11].

It seems that we can now observe a slight change in perception of what meat is, and what its nutritious values are, especially in comparison to times before the transition, when a deficiency in the availability of meat products, meant it was associated with "abundance, protection against hunger, strength and vitality" [12, p.339]. The continuing interest in healthy eating, has made some Polish people suspicious about eating meat altogether ${ }^{10}$.

Warde indicates that the anxiety about food can also stem from paying greater attention to the body shape nowadays [9, p.23]. Referring to the discourse of slimness Bauman notices: "Slimness, with its overtones with youthfulness and of proper self-discipline, is a much desired condition for many people" [13, p. 42]. This is reflected in the answers of those of my research participants, who had decided to go on a diet. Among the most popular motivations to go on a diet there were the desire to lose weight, to look better and to improve their sense of well-being. The ideal of slim body shape seemed to play an important role as a motivating factor.

My research participants obtained their information about dieting from the mass media and from people who occupied their immediate environment. However, they seemed to choose their diets consciously. Only one research participant, as mentioned before, admitted to having gone on a diet due to the fashion for dieting in their social environment.

It is also important to note that some participants sought professional advice, which they achieved though specialist books on the subject of dieting, or by visiting specialists such as doctors, dieticians or even Chinese medicinal advisers. This can be interpreted as referring to expert knowledge in searching for the most appropriate option in the situation of diversity of "authorities", which was further described by Giddens [1,2].

With the development of a free market economy, the influence of the mass media, advertising and globalization, there is a greater variety of options to choose from. Also the knowledge concerning the relationship between food and health is once more under a process of transformation. It is an ongoing evolution requiring constant following and updating. As a result, both "local" and "global" factors shape the commonly shared beliefs about food and health. On the one hand, they are nationally specific and locally shared, while on the other, the views presented through the mass media, armed with the tendencies of a global characterization, mold them appropriately and accordingly. Examples of the "local"

10 Although only one percent of the Polish people declare that they are vegetarians $[3$, p.11]. dimensions in a Polish context are readily identifiable by those who participated in the research. Yet at the same time, some of those beliefs expressed should be considered "worldwide" (e.g. the discourse of slimness, the discourse of healthy eating itself or the ecological trend in nutrition). It seems important role to popularize the "global" part of this knowledge, playing the 'new media', particularly that of the Internet.

In this way, the relationship between food and health is again revised, with traditional forms of cooking either reinterpreted or incorporated into one's lifestyle, that, or they are simply rejected. As Giddens [2, p.5] puts it: "The more tradition loses its hold, the more daily life is reconstituted in terms of the dialectical interplay of the local and the global, the more individuals are forced to negotiate lifestyle choices among the diversity of options".

\section{Conclusions}

The research participants perceived healthy eating as a way of life. They treated it as a part of their lifestyles. They were very conscious of the relationships between nutrition and health. Their knowledge of the rules of healthy eating proved to be very up to date. In their choices of healthy products, they referred both to the elements of expert knowledge as well as to the widely shared apparent knowledge. Some of the beliefs expressed by my research participants proved to be popular within the whole population of the Polish people. What is more, the research participants were accustomed with the latest trends in nutrition and dieting fashions, but they were rather reluctant to follow the fashions. They seemed to choose their dieting and eating patterns consciously, pointing out, that the proper nutrition should be based on a well-balanced program of eating, one that should accordingly respond to the individual nutritional needs of one's body. The participants also raised the issue of the quality of the food they consumed. They expressed their uncertainty about the positive effects of eating certain products on health, especially meat.

\section{REFERENCES}

[1] Giddens A., Europe in the Global Age. Polity Press, Cambridge, 2007.

[2] Giddens A., Modernity and Self Identity. Self and Society in the Late Modern Age. Polity Press, Cambridge, 1991.

[3] CBOS's Research Report No.: 115/2014 (ISSN: 2353-5822), "Zachowania żywieniowe Polaków" (Nutritional Behaviors of the Poles), Online available: http://badanie.cbos.pl/details. asp?q=a1 \&id $=5054$.

[4] Domański H., Karpiński Z, Przybysz D., Straczuk J., Wzory jedzenia a struktura społeczna (Patterns of Eating and Social Structure), Scholar Publishing, Warsaw, 2015. 
[5] Given L. (ed.), The Sage Encyclopedia for Qualitative Research Methods, Vol. 1, Sage Publications, Los Angeles, London, New Delhi, Singapore, 2008.

[6] Ryan G.W., Bernard H. R. (2000), Data Management and Analysis Methods, in: Denzin N.K, Lincoln Y. S. (ed.), Handbook of Qualitative Research, Sage Publications, Thousand Oaks, London and New Delhi, 2000.

[7] Given L. (ed.), The Sage Encyclopedia for Qualitative Research Methods, Vol. 1, Sage Publications, Los Angeles, London, New Delhi, Singapore, 2008.

[8] Mennell S., All Manners of Food. Eating and Taste in England and France from the Middle Ages to the Present, Basil Blackwell, Oxford 1985.

[9] Warde A., Consumption, Food and Taste, Sage Publications, Thousand Oaks, London and New Delhi, 1997.

[10] Cichecka J. (2013), Dystynkcja i dieta: rola kapitału kulturowego w procesie kształtowania upodobań żywieniowych (Distinction and Diet: The Role of Social Capital in the Process of Shaping Eating Preferrences), in: Tobiasz-Adamczyk B. (ed.), Od socjologii medycyny do socjologii żywienia (From Sociology of Medicine to Sociology of Food), Jagiellonian University Publishing, Kraków, 147-162, 2013.

[11] Beck U., The Risk Society: Towards a New Modernity, Sage Publications, Los Angeles, London, New Delhi, Singapore, Washington DC, 1992.

[12] Stańczak-Wiślicz K. (2014), Kryzysowe praktyki kulinarne w Polsce lat 80-tych XX wieku na łamach ówczesnej prasy kobiecej (The 'Crisis' Culinary Practices in Poland in the 1980's), in: Jarecka U., Wieczorkiewicz A. (ed.), Terytoria smaku: studia $\mathrm{z}$ antopologii i socjologii jedzenia (Teritiories of Taste: Studies in Anthropology and Sociology of Food), Instytut Etnologii i Antropologii Kulturowej UW, IFiS PAN, Warsaw, 321-348, 2014.

[13] Bauman Z., Thinking Sociologically, Basil Blackwell, Oxford 1990 